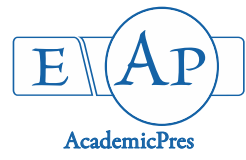

\title{
Insight into Re-emergence of Cassava Brown Streak Disease: the Need to explore Diverse Approaches for Effective Control
}

\author{
John O. OLADOKUN ${ }^{1,2 *}$ \\ ${ }^{1}$ Assam Agriculture University, Faculty of Agriculture, Department of Plant Pathology, Jorbat, 785013, Assam, India \\ ${ }^{2} J u s t i c e$ Development and Peace Programme, Department of Rural Development Programme, P.M. B. 1480, Oyo, Oyo State, \\ Nigeria; deejite1086@gmail.com ("correspondingauthor)
}

\begin{abstract}
The consumption of cassava crop per capita calories in many Africa countries ranked it as the second most important staple food crop. Despite its diverse utilities, the yield potential of cassava is greatly hampered by viral diseases and these differ from country to country, depending on the type of viruses present. Unfortunately, the recent sudden re-emergence of cassava brown streak disease (CBSD) in East and Central Africa is currently gaining more aggressive international attention in Africa and other concerned countries, due to the significant economic yield losses imparting to most poor resource farmers fields. However, selfless efforts from scientific researches to manage CBSD, including recommendations, still seems not to be complimented as expected with pro-active measures from relevant stakeholders, nevertheless the concerned farmers. Overall, the present review revisited a brief glance of the historical development of CBSD, progresses made so far with respect to management strategies. Even more, the paper suggests opinions which could be explore by the ones interested to help within research findings, as well as to bring the awareness and to prevent further spread in countries and/or regions where there is currently the outbreak of CBSD and which had not been yet affected.
\end{abstract}

Keywords: Cassava; farmers; management strategies; stakeholders; viral disease; yield potential

\section{Introduction}

Cassava (Manihot esculenta Crantz), the crop which seems to be the "food for the poor masses" has now become a multipurpose crop that responds to the priorities of many developing countries, to trends in the global economy and to the challenge of climate change (Jarvis et al., 2012; FAO, 2013). It is now considered to be the second most staple food crop of Africa, following maize (Zea mays) in terms of it per capita calories consumed (Nweke, 2004). It can be processed into different forms in homes of most local growers for consumption (about 90\%) or for the industrial usage such as refined starch and sometimes alcohol, among others. Farm animals are also not left out of benefiting from the nutritional components of cassava, by feeding on the peels (around 10\%). And so, the qualities of cassava have made it highly attractive to smallholder farmers and the cassava's importance in agricultural sector has changed dramatically with continuous increase in its cultivation in Africa. The output of cassava produce in 2011 put together has increased most markedly in sub-Saharan Africa, which harvested 140.9 million tonnes more than half of the global harvest (FAO, 2013). Africa produces over one-half of global cassava, of about $57 \%$ (Bennett, 2015); however, the continent's average fresh yield of 9.9 tonnes per hectare lags behind potential yields of 15-40 tonnes per hectare achieved under experimental conditions. Fermont et al. (2009) believed that this significant sharp declined could be attributed to many factors including restricted access to labour, poor soil quality, crop diseases, premature harvesting and many other factors.

Seventeen different cassava viruses have been described, out of which eight are known to occur in Africa alone (Thresh et al., 1994). Despite the continuous increase in cassava cultivation in Africa and constant growing areas, of major biotic factor contributing to cassava reduced yield potentials in many Africa countries are Cassava mosaic disease (CMD) caused by Cassava mosaic virus in the genus Begomovirus transmitted by whiteflies, and cassava brown streak disease (CBSD) caused by Cassava brown streak virus (Genus: Ipomovirus) which is believed to be transmitted by whiteflies (Gary Foster, unpublished report) and which have been given more attention in Africa for many years and still gaining much more attention. According to Thresh et al. (1997) perspective, assumable estimated yield losses due to CMD infection alone in Africa ranged between 15-25\% equivalents to 15 - 28 million tonnes. 
Nevertheless, CBSD, which is the subject of the present review, in the most sensitive cultivars, can reduce root weight by up to $70 \%$ with necrosis developing at 6 months post-planting (Hillocks et al., 2001).

It was aimed therefore in the present investigation to show brief key historical development of CBSD, what led to the emergence and sudden re-emergence after years of purse in spread to areas where there were no records of the infection. The study also includes the reasons why significant scientific effort towards effective prevention and management strategies seem not to compliment the output obtained by many cassava growers. It is of hope that these views would be looked into and better redefined. It is therefore important as a matter of urgency, to unanimously intensify a good collaboration between all relevant persons involved, so as to help the larger poor resource cassava growers to mitigate this disease causing low output of the crop.

Revisit to the historical development of CBSD emergence and re-emergence

The early emergence and distribution of CBSD could be traced back to Story (1936), who noted the first record from the foothills of the Usumbara Mountains of Tanganyika which is now called Tanzania. Later, Nichols reported in 1950 that CBSD was endemic in all East African coastal cassava growing areas, from the border of North-East of Kenya and Mozambique, which was widespread at Nyasaland, now known as Malawi. Similarly, surveys for CBSD have also confirmed the occurrence in Tanzania and Malawi (Sweetmore, 1994; Hillock et al., 1996, 1999; Legg and Raya, 1998) and Uganda (Thresh et al., 1994) as evident from many reports on CBSD in literature.

The distribution of CBSD was believed to differ within altitude in these regions. In the early 2000's, CBSD incidences as reported in Malawi reached about $75 \%$ in many fields surrounding Lake Malawi and Mozambique infecting cassava plants (Hillocks and Jennings, 2003; Hillocks et al., 2002).

CBSD can affect all parts of cassava plants, in a different degree, depending on the environmental conditions, growth stage of the crop, relative to the time of infection and the sensitivity of the cultivar grown (Hillocks and Thresh, 2000). Symptoms on leaf could appear chlorotic around the secondary veins or circular patches between the main veins, the disease may affect the lamina if it is in the advanced stage of infection (Nichols, 1950). On young green stems, symptoms appear as purple or brown lesions and necrotic, whereas in tubers the symptom of CBSD is characterized by a stained brown or black tissue surrounding the tips, while below the tips, the cortex is necrotic. This then turns the starch bearing tissue of the cassava tuber sometimes to blue/black streaks (Hillocks and Thresh, 2000).

In 2004, the re-emergence of CBSD across East and Central Africa was noticed, especially in Uganda, on cassava plants expressing CBSD symptoms as confirmed by Alicai $e t$ al. (2007). However, the source of introduction to Uganda was not clear, even though the increase in incidence of CBSD from $12 \%$ in 2008 to $27 \%$ in 2011 (Tomlinson et al. (2018), personal communication with Alicai Titus) was noted. Other African countries where CBSD incidences have increased within a short period of time in the early 2000's include: Tanzania and Kenya (Ntawuruhunga and Legg, 2007; Mware et al., 2009; Legg et al., 2011), Burundi (Bigirimana et al., 2011), Rwanda (FAO, 2011), Eastern Democratic Republic of Congo (Mulimbi et al., 2012) and Mayotte Island (Roux-Cuvelier et al., 2014).

It should be of note that as long as cassava cultivation continued to be on an increase in Africa, there is high tendency of transferring CBSD from location to locations due to stem cuttings exchange by the growers who had no knowledge of the implication the disease might cause.

\section{Underlying problem for non-extensive successes of scientific research}

The non-judicious use of chemicals by many farmers to protect their cassava fields with the intent of having healthy plants might unknowingly have contributed greatly to the resistance of whiteflies which in-turn could have resulted in the increase in their populations. Tomlinson et al. (2018) in their publication in the Journal of Molecular Plant Pathology have pointed out some early control measures many CBSD infecting countries have taken in the beginning from 1930's. These methods as gathered include the establishment of cassava breeding programme, like for instance that which was launched in Tanzania (Jennings, 1957; Nichols, 1946) and is still ongoing (Kawuki et al., 2016).

Even so, to date, evidence showed that there is no cassava cultivar with a high level of CBSD resistance available to farmers (Abaca et al., 2013). Since there are no complete cures for such a virus that attacks plants and cause disease(s), the alternative is to manage and control the vector responsible for the disease, to obtain the lowest (minimum) spread. However, in search for solutions, breeding resistance cultivars still remain the best option to prevent CBSD. In this regard, efforts through the use of markers such as simple sequence repeats (SSRs) and single nucleotide polymorphisms (SNPs) in marker assisted breeding (MAB) techniques are used to map and identify quantitative traits associated with CBSD tolerance across diverse African farmer-preferred cultivars (Prochnik et al., 2012; Patil et al., 2015); such methods are gaining more attention by cassava breeders. It is with optimism that if these markers are validated, the traits will be useful and could be combined into cultivars for effective and durable CBSD tolerance (Pariyo et al., 2013).

Tomlinson et al. (2018) gave an insight on the extents of research conducted from 1936 to 1990 's when the disease emerged in Africa and as well the re-emergence of the same disease after the mid 1990's. Put together, a total of two hundred and seventy seven (277) articles on CBSD were compiled and published, which could have been a pointer to appropriate measure in advance for the outbreak. No doubt, researchers are never at rest to find solutions to this disease. However, personal opinion is that the rate of research in different Africa countries does not compliment the effort entrusted in it. In many countries, governments at different levels have instituted department and competent personnel that is expected to work directly with the rural farmers. But, the limitation of those departments to function efficiently to their expectations is influenced based on their personal 
28

reservations. This in turn lessens their outreach to larger target groups of farmers in terms of disseminating research information, especially the rural farmers that engage and contributed to the larger percentage of production. Somehow, these have weakened the extension pathology outreach of disseminating vital information's to the farmers.

On the part of the scientists, focus has been to carry out researches that will mitigate the underlying diseases such as CBSD and the transfer of results and knowledge gained in scientific communities, and most especially, making recommendations to the policy makers for actions to be taken upon. Even so, little or no follow up with the policies makers, based on the disseminated findings, could have contributed to non-appreciable success. And so, it will be appropriate for researchers to identify relevant stakeholders that will promote their findings, both at the inception of their research designing, as well as to the end objectives. In addition, it is generally of the belief that over $70 \%$ of farmers who are of the generation of the late 1900's are illiterate, even though excellent in what work they do, ranging from cultivation to harvesting. Unfortunately, these farmers find it difficult to change from their old ways of cultivation inherited from their forefathers, which may be directly contributing to the favourable environment that support CBSD development. And this has been one of the major limitations to numerous research outputs usage conducted by scientists coupled with poor extension services. For instance, many of those farmers in the class by personal experience, found it difficult to accept improved varieties of cassava stems they are not familiar with, and preferred those they have been recycling for planting over years, until any member of their group attest to his/her yield increment. Not that alone, because of unfulfilled promises made to farmers by present and past administrations at all levels, with respect to their sustainability, such actions have equally further triggered the lack of trust from different quarters, irrespective of how beneficial it could be. Nevertheless, all efforts from all concerned must be put together to combat CBSD and other diseases affecting agricultural crops.

\section{Proposed way forward in mitigating CBSD spread as a case study}

As long as everyone involved in the chain of agriculture would admit their weaknesses and strengthen it for the benefit of the general public, including farmers and producers that offer food supplies thus food security, then the control of further spread of CBSD would be prevented. As it is scientifically known by now, one method cannot solve the problem of any disease.

It should also be addressed that other cassava producing countries where CBSD have not been reported, should try and initiate programmes focusing on prevention of emergence of CBSD. Consequently, there have been different initiatives approaches in some African countries which have brought cassava growers closer to the researchers and restored little trust in what the government can do. For instance, in Nigeria, approaches used in some of the ongoing collaborative cassava projects under the International
Institute of Tropical Agriculture (IITA) and some NonGovernmental Organizations (NGOs), as well as within departments of Rural Development Programme under the Justice Development and Peace Programme, in all SouthWest Nigeria. Their aims are (1) Cassava seed system production funded by Catholic Renewal Services, (2) Harvestplus, (3) Yam Improvement for Income and Food Security in West Africa (YIIFSWA), (4) Cassava Weed Management Programme (CWMP). These joint collaborative efforts have fostered cordial and results are driven through solid relationship between the researchers in the institution, stakeholders at various levels and farmers of all kinds. The projects were designed in such way that researchers and farmers played different roles in conjunction with the NGOs, the group that farmer's listens to.

If possible, trusted NGOs who work closely or directly with groups of farmers should be incorporated in some components of the research, perhaps they may be used as the extension personnel to disseminate the outcome of the research. Also, appropriate sensitization of farmers using their formed group on the implication on how it could affect their cassava yield and income should the responsibility of the policy makers, should be intensify. In case there is need to support the farmers, such as distribution of diseased free planting materials or other inputs, reliable NGOs can act as mediator between the researchers and the relevant stakeholders through the governments.

A good example of efficient measures undertaken and communication are Global Cassava Partnership for the 21st Century (Tomlinson et al., 2018) and Connected Network for Africa Borne Viruses, CONNECTED (with headquarter situated at University of Bristol, UK), among others.

\section{Conclusions}

Towards effective management, to prevent cassava plants from present CBSD spread to other countries or in areas in Africa with higher production capacity (especially West African countries like Nigeria, Ghana and so on) where there is no occurrence of the disease yet, but with the tendency of attack, there is need to utilize the opportunities of the recent development made through research. Also, controlling outbreak of diseases such as CBSD requires joint collaboration. Until collaboration is maintained, production or designed research programmes cannot be of good comparative advantage to the final users as expected. This will require experts, farmers across diverse backgrounds and countries to openly communicate, engage, share data and collaborate through networks. Hence, effective preventive mechanism should be embraced.

\section{Acknowledgements}

The present article received no specific grant from any funding agency in the public, commercial, or not-for-profit sectors. 


\section{References}

Abaca A, Kawuki R, Tukamuhabwa P, Baguma Y, Pariyo A, ... Bua A (2013). Genetic relationships of cassava genotypes that is susceptible or tolerant to cassava brown streak disease in Uganda. Journal of Agricultural Science 5(7):107.

Alicai T, Omongo CA, Maruthi MN, Hillocks RJ, Baguma Y, ... Colvin J (2007). Re-emergence of Cassava brown streak disease in Uganda. Plant Disease 91:2429.

Bennett B (2015). Guest editorial: smallholder cassava production and the cassava processing sector in Africa. Food Chain 5:1-3.

Bigirimana S, Barumbanze P, Ndayihanzamaso P, Shirima R, Legg JP (2011). First report of Cassava brown streak disease and associated Ugandan cassava brown streak virus in Burundi. New Disease Report 24(26):10440588.

Fermont AM, van Asten PJA, Tittonell P, van Wijk MT, Giller KE (2009). Closing the cassava yield gap: an analysis from smallholder farms in East Africa. Field Crop Research 112:2436.

Food and Agriculture Organization (2011). Cassava virus on verge of epidemic in East Africa: experts urge funding, swift action to protect staple food crop. Rome: Food and Agricultural Organization.

Food and Agriculture Organization (FAO)(2013). Save and grow Cassava: A guide to sustainable production intensification. Rome: Food and Agriculture Organization of the United Nations.

Hillocks RJ, Jennings D (2003) Cassava brown streak disease: a review of present knowledge and research needs. International Journal of Pest Management 49:225-234.

Hillocks RJ, Thresh JM, Tomas J, Botao M, Macia R, Zavier R (2002). Cassava brown streak disease in northern Mozambique. International Journal of Pest Management 48:178-181.

Hillocks RJ, Thresh JM (2000). Cassava mosaic and Cassava brown streak virus diseases in Africa: A comparative guide to symptoms and etiologies. Roots 7(1):1-8.

Hillocks RJ, Raya MD, Mtunda K, Kiozia H (2001). Effects of brown streak virus disease on yield and quality of cassava in Tanzania. Journal of Phytopathology 149:389-394.

Hillocks RJ, Raya M, Thresh JM (1996). The association between root necrosis and above-ground symptoms of brown streak virus infection of cassava in southern Tanzania. International Journal of Pest Management 42:285-289.

Hillocks RJ, Raya M, Thresh JM (1999). Factors affecting the distribution, spread and symptom expression of Cassava brown streak disease in Tanzania. International Journal of Pest Management 42:285-289.

Jarvis A, Ramirez-VillegasJ, Herrera Campo BV, Navarro-Racines C(2012). Is cassava the answer to African climate change adaptation? Tropical Plant Biology 5:9-29.

Jennings DL (1957). Further studies in breeding cassava for virus resistance. East African Agricultural Journal 22:213-219.

Kawuki RS, Kaweesi T, Esuma W, Pariyo A, Kayondo IS, ... Baguma Y (2016). Eleven years of breeding efforts to combat Cassava brown streak disease. Breeding Science 66:560-571.

Legg JP, Jeremiah SC, Obiero HM, Maruthi MN, Ndyetabula I, ... Lava
Kumar P (2011). Comparing the regional epidemiology of the Cassava mosaic and Cassava brown streak virus pandemics in Africa. Virus Research 159:161-170.

Legg JP, Raya MD (1998). Survey of cassava virus diseases in Tanzania. International Journal of Pest Management 44:17-23.

Mulimbi W, Phemba X, Assumani B, Kasereka P, Muyisa S, ... Thom FEF (2012). First report of Ugandan cassava brown streak virus on cassava in Democratic Republic ofCongo. New Disease Report 26:11.

Mware BO, Ateka EM, Songa JM, Narla RD, Olubayo F, Amata R(2009). Transmission and distribution of cassava brown streak virus disease in cassava growing areas of Kenya. Journal of Applied Bioscience 16:864 870 .

Nichols RFW (1946). Breeding cassava for virus resistance. East African Agricultural Journal 12:184194.

Nichols RFW (1950). The brown streak disease of cassava. East African Agricultural Journal 15:154160.

Ntawuruhunga P, LeggJ (2007). New spread of Cassava brown streak virus disease and its implications for the movement of cassava germplasm in the East and Central African region. Crop Crisis Control C3P Project Report. http: //c3 project.iit a.org/D oc/A25-CB SDbriefM ay6.pdf.

Nweke F (2004). New challenges in the cassava transformation in Nigeria and Ghana. International Food Policy Research Institute 118.

Pariyo A, Tukamuhabwa P, Baguma Y, Kawuki RS, Alicai T, ... Rabbi IY (2013). Simple sequence repeat (SSR) diversity of cassava in South, East and Central Africa in relation to resistance to Cassava brown streak disease. African Journal of Biotechnology 12:4453-4464.

Patil BL, Legg JP, Kanju E, Fauquet CM (2015). Cassava brown streak disease: a threat to food security in Africa. Journal of General Virology 96:956-968.

Prochnik S, Marri PR, Desany B, Rabinowicz PD, Kodira C, ... Rounsley S (2012.) The Cassava genome: current progress, future directions. Tropical Plant Biology 5:88-94.

Roux-Cuvelier M, Teyssedre D, Chesneau T, Jeffray C, Masse D, ... LettJM (2014). First report of Cassava brown streak disease and associated Ugandan cassava brown streak virus in Mayotte Island. New Disease Report 30:28.

Storey HH (1936). Virus diseases of East African plants. East African Agricultural Journal 1:333-337.

Sweetmore A (1994). Adaptation and development of diagnostics reagents for cassava brown streak virus for use in less-developed countries. Natural Resources Institute Report,pp 23.

Tomlinson K, Bailey AM, Alicai T, Seal S, Foster GD (2018). Cassava brown streak disease: historical timeline, current knowledge and future prospects. Molecular Plant Pathology 19(5):1282-1294.

Thresh JM, Fargette D, Otim-Nape GW (1994). The viruses and virus diseases of cassava in Africa. African Crop Science Journal 2:459-478.

Thresh JM, Otim-Nape GW, Legg JP, Fargette D (1997). African cassava mosaic disease: What is the magnitude of the problem? African Journal of Root and Tuber Crops Special Issue: Contribution of Biotechnology to Cassava in Africa. In: Thro RM, Akoroda MP (Eds). Proceedings of the Cassava Biotechnology Network, Third International Scientific Meeting. Kampala, Uganda 26-31 August 1996pp 13-19. 